\title{
WORIPLLEE SOLDIONS
}

\section{No-nose Saddles for Preventing Genital Numbness and Sexual Dysfunction from Occupational Bicycling}

\section{Summary}

Workers who ride a bicycle as part of their job may be at risk for genital numbness or more serious sexual and/or reproductive health problems from pressure in the groin (perineum) from the traditional bicycle saddle. NIOSH has conducted studies that have demonstrated the effectiveness of no-nose bicycle saddles in reducing pressure in the groin and improving the sexual health of male bicycle patrol police officers. While most workers in jobs that involve bicycling are men, recent evidence suggests that no-nose bicycle saddles may also benefit women.

\section{Description of Exposure}

About 40,000 workers in public safety occupations ride bicycles as part of their job. They include police officers, emergency medical service personnel (EMSs), and security staff who patrol by bicycle. A number of these workers have reported groin/genital numbness and
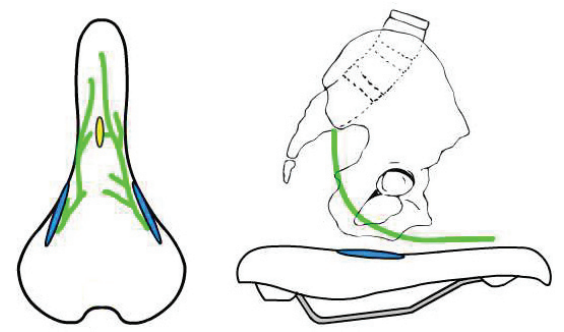

Figure 1. Nerves and arteries for the genitals (shown in green) compressed under the traditional saddle nose. The blue region represents the contact areas on the sit bones. The yellow region represents the pubic bone. The pelvis is shown in the side view.

more severe sexual problems related to prolonged use of a bicycle saddle in their work [NIOSH 2000]. In a study conducted by Schrader et al. [2002], police bicycle patrol officers reported spending an average of about 25 hours per week sitting on a bicycle saddle. Many of them also ride a bicycle for recreation while off duty, and therefore may spend more than 25 hours per week on a bicycle saddle.

The traditional bicycle saddle has a narrow nose that protrudes under the groin as the cyclist straddles the bicycle. Ideally, the weight of the cyclist should be supported on the saddle under the pelvic sit bones. However, part of the weight is supported where the groin contacts the saddle nose. Bearing weight on this region of the saddle compresses the nerves and arteries in the groin (see Figures 1 and 2). These nerves and arteries run through the groin between the sit bones to the genitals. Pressure on these nerves and arteries over time may lead to a loss of sensation and a decrease in blood supply to the genitals. This can contribute to the sexual and reproductive health effects that have been reported.

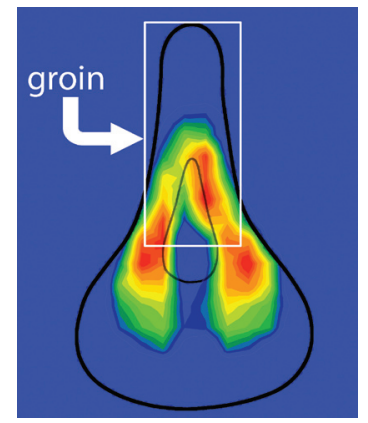

Figure 2. Example of pressure measured on a traditional saddle with a protruding nose. The white box shows the groin region. The blue color is the lowest pressure, followed by green, yellow, orange, and red (highest pressure). This saddle has a cut-out hole as shown by the thinner dark outline of the saddle.
DEPARTMENT OF HEALTH AND HUMAN SERVICES Centers for Disease Control and Prevention National Institute for Occupational Safety and Health

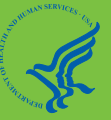

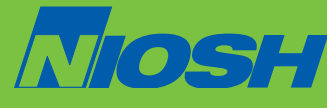




\section{NIOSH Studies}

NIOSH studies [2000, Schrader et al. 2002] showed that male bicycle patrol security officers who complained of groin numbness had night erections that lasted less time than those of a similar group of non-bicycling men. Other NIOSH studies [Lowe et al. 2004; Schrader et al. 2008], showed that pressure on a traditional (nosed) bicycle saddle in the area under the bicyclist's groin is typically 2.90 pounds per square inch during cycling and may reach as high as 5.37 pounds per square inch. (As a point of reference, the pressure on an arm blood pressure cuff needed to restrict blood flow in the arteries is about $120 \mathrm{~mm} \mathrm{Hg}$, which is equal to 2.32 pounds per square inch). This level of pressure is affected by the weight and body shape of the cyclist, the shape and cushioning of the saddle, and the degree to which the cyclist's body is tilted forward.

Fewer studies of the effects of bicycle saddle use on female cyclists have been conducted. However, recent evidence suggests that women cyclists may also be at risk for a decrease in sensation of their genitals from use of a traditional nosed bicycle saddle [Guess et al. 2006].

\section{Reducing Pressure in the Groin from the Bicycle Saddle}

\section{The no-nose bicycle saddle}

A number of manufacturers have designed bicycle saddles to support the weight of the cyclist on their sit bones without a narrow nose of the saddle protruding forward under the groin region. A no-nose bicycle saddle is designed so that the portion of the nerves and arteries for the genitals that are forward of the sit bones are not compressed against any part of the saddle surface (see Figure 3). A no-nose bicycle saddle should have no saddle material protruding between the thighs of the cyclist to create pressure in the groin.

\section{NIOSH studies of no-nose saddles}

A study by NIOSH [Lowe et al. 2004] showed that saddles without the protruding nose greatly reduced pressure in the groin that compresses the nerves and arteries for the genitals. In a more recent NIOSH study [Schrader et al. 2008], the no-nose saddles were associated with pressure in the groin region of 1.02 pounds per square inch. In a typical pressure picture for a no-nose saddle, there is very little pressure forward of the sit bones (see Figure 4). The pressure on the nerves and arteries for
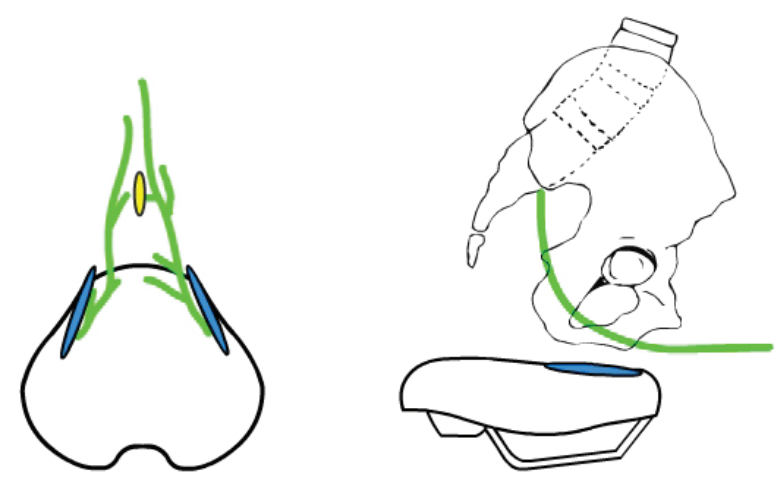

Figure 3. Removal of the protruding saddle nose reduces pressure under the nerves and arteries for the genitals. See Figure 1 for further description.

the genitals may be even lower than 1.02 pounds per square inch because some of the measured pressure was caused by the back of the thighs making contact with the rounded-off front of the no-nose saddle. The study showed that the no-nose saddle reduced pressure in the groin by at least $65 \%$ (see Figure 5). In the 2008 NIOSH study, more than $90 \%$ of officers on bicycle patrol who tried a no-nose saddle were still using the saddle after 6 months. These officers believed that no-nose bicycle saddles could be used safely and effectively in their work. Several of these officers said that it took some time to get used to the no-nose saddle because it has a different feel than a traditional saddle.

\section{Recommendations}

Contrary to some cyclists' belief, it is not normal for any part of your body to go numb or lose feeling. Numbness in the groin or genitals is a warning sign that should not be ignored. Workers who ride a bicycle as part of their

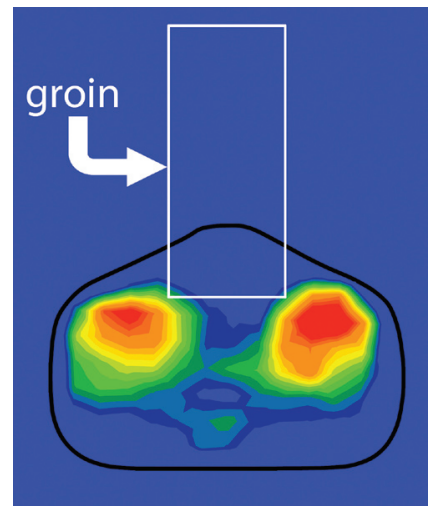

Figure 4. Example of pressure measured on a no-nose saddle. In this example there is almost no pressure in the groin region. 


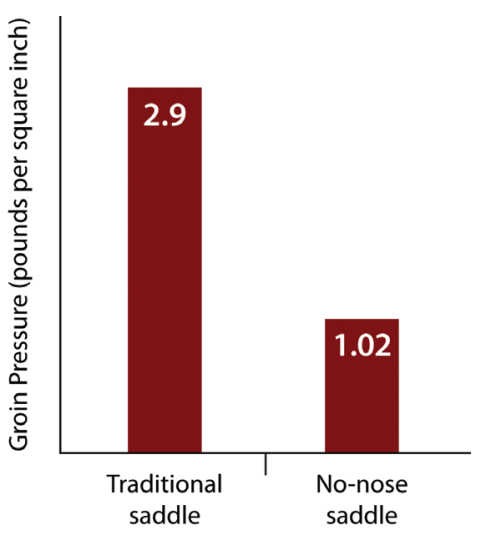

Figure 5. Comparison of groin pressure for a traditional and no-nose saddle.

job ${ }^{*}$ can take the following steps to help prevent sexual and reproductive health problems:

- Use a no-nose saddle for workplace bicycling. Give yourself time to get used to riding with a no-nose saddle. At first, it may seem very different from the saddle you have used in the past. No-nose saddles may not always be available at retail bicycle shops, but they are readily available for purchase through the Internet.

- Seek guidance on proper bicycle fit from a trained bicycle fit specialist. Use of a no-nose saddle may require different saddle height and angle adjustments. Be sure that the no-nose saddle is adjusted according to the manufacturer's instructions.

- Dismount the bicycle when at a standstill. Do not lean against a post or other object to stay seated on the bicycle saddle when you are not riding.

- Dismount the bicycle if you begin to have numbness, tingling, or loss of feeling in any part of your body.

*NIOSH has not studied competitive cycling and can not make recommendations for the relatively small number of workers who ride a bicycle competitively in their occupation.

\section{Acknowledgments}

The principal contributors to this publication were Steven M. Schrader, Brian D. Lowe, and Michael J. Breitenstein of the Division of Applied Research and Technology, National Institute for Occupational Safety and Health. The International Police Mountain Bike Association has assisted NIOSH in much of the research conducted on this topic.

\section{References}

Guess MK, Connell KA, Schrader SM, Reutman SR, Wang A, Lacombe JA, Toennis C, Lowe BD, Melman A, Mikhail MS [2006]. Genital sensation and sexual function in female bicyclists and runners: Are your feet safer than your seat? J Sexual Med 3(6):1018-1027.

International Police Mountain Bike Association [2008]. The complete guide to public safety cycling. $2^{\text {nd }}$ ed. Sudbury, MA: Jones and Bartlett Publishers.

Lowe BD, Schrader SM, Breitenstein MJ [2004]. Effect of bicycle saddle designs on the pressure to the perineum of the bicyclist. Med Sci Sports Exerc 36(6):1055-1062.

NIOSH [2000]. Health Hazard Evaluation Report: City of Long Beach Police Department, Long Beach, CA. By Schrader SM, Breitenstein MJ, Lowe BD. Cincinnati, OH: U.S. Department of Health and Human Services, Centers for Disease Control and Prevention, National Institute for Occupational Safety and Health, HETA 2000-0305-2848.

Schrader SM, Breitenstein MJ, Clark JC, Lowe BD, Turner TW [2002]. Nocturnal penile tumescence and rigidity testing of bicycling patrol officers. J Androl 23(6):927-934.

Schrader SM, Breitenstein MJ, Lowe BD [2008]. Cutting off the nose to save the penis. J Sexual Med 5:1932-1940. 


\section{DEPARTMENT OF HEALTH AND HUMAN SERVICES}

Centers for Disease Control and Prevention

National Institute for Occupational Safety and Health

4676 Columbia Parkway

Cincinnati, OH 45226-1998

Official Business

Penalty for Private Use $\$ 300$

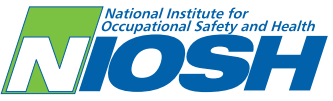

\section{For More Information}

More information about bicycle saddles and reproductive health can be found at the following Web site: http://www. cdc.gov/niosh/topics/bike/.

The reproductive health topic page can be found at the following Web site: http://www.cdc.gov/niosh/topics/repro/.

A video demonstration of saddle pressure on no-nose saddles can be found at the following Web site: http://video.cdc.gov/ ramgen/niosh-video/saddle_pressure.rm.

For copies of the NIOSH Health Hazard Evaluation report this document cites, contact NIOSH at:

Telephone: 1-800-CDC-INFO (1-800-232-4636)

TTY: 1-888-232-6348

E-mail: cdcinfo@cdc.gov

or visit the NIOSH Web site at www.cdc.gov/niosh

For a monthly update on news at $\mathrm{NIOSH}$, subscribe to NIOSH $e$ News by visiting www.cdc.gov/niosh/eNews.
Mention of any company or product does not constitute endorsement by NIOSH. In addition, citations to Web sites external to NIOSH do not constitute NIOSH endorsement of the sponsoring organizations or their programs or products. Furthermore, NIOSH is not responsible for the content of these Web sites.

This document is in the public domain and may be freely copied or reprinted. NIOSH encourages all readers of the Workplace Solutions to make them available to all interested employers and workers.

As part of the Centers for Disease Control and Prevention, NIOSH is the Federal agency responsible for conducting re- search and making recommendations to prevent work-related illnesses and injuries. All Workplace Solutions are based on research studies that show how worker exposures to hazardous agents or activities can be significantly reduced.

No-nose Saddles for Preventing Genital Numbness and Sexual Dysfunction from Occupational Bicycling

DHHS (NIOSH) Publication No. 2009-131 